DIVISION OF THE HUMANITIES AND SOCIAL SCIENCES

CALIFORNIA INSTITUTE OF TECHNOLOGY

PASADENA, CALIFORNIA 91125

THE EFFECT OF VOTER IDENTIFICATION LAWS ON TURNOUT

R. Michael Alvarez

California Institute of Technology

Delia Bailey

Washington University in St. Louis

Jonathan N. Katz

California Institute of Technology

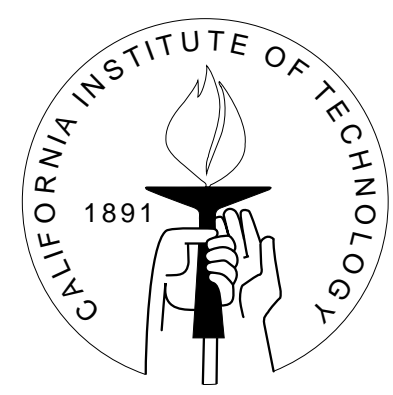

SOCIAL SCIENCE WORKING PAPER 1267R

January, 2008 


\title{
The Effect of Voter Identification Laws on Turnout*
}

\author{
R. Michael Alvarez Delia Bailey Jonathan N. Katz
}

\begin{abstract}
Since the passage of the "Help America Vote Act" in 2002, nearly half of the states have adopted a variety of new identification requirements for voter registration and participation by the 2006 general election. There has been little analysis of whether these requirements reduce voter participation, especially among certain classes of voters. In this paper we document the effect of voter identification requirements on registered voters as they were imposed in states in the 2000 and 2004 presidential elections, and in the 2002 and 2006 midterm elections. Looking first at trends in the aggregate data, we find no evidence that voter identification requirements reduce participation. Using individual-level data from the Current Population Survey across these elections, however, we find that the strictest forms of voter identification requirements - combination requirements of presenting an identification card and positively matching one's signature with a signature either on file or on the identification card, as well as requirements to show picture identification - have a negative impact on the participation of registered voters relative to the weakest requirement, stating one's name. We also find find evidence that the stricter voter identification requirements depress turnout to a greater extent for less educated and lower income populations, for both minorities and non-minorities.
\end{abstract}

*This paper replaces an earlier version with the same title that was distributed October, 2007. Previous versions of this paper were presented at the 2007 Summer Methods Meeting, The Society for Political Methodology, Pennsylvania State University; the 2007 Annual Meeting of the American Political Science Association, Chicago, Illinois; and at the Second Annual Conference on Empirical Legal Studies, New York University Law School. We thank Shigeo Hirano, Thad Hall, and Andrew Martin who provided comments at each conference respectively, as well as conference participants. We also thank Clark Benson, Andrew Gelman, Sam Hirsch, and Nate Persily for helpful comments and conversations. We thank the Carnegie Corporation of New York and the John S. and James L. Knight Foundation for their support of our research through grants to the Caltech/MIT Voting Technology Project. The analysis presented here, and the interpretations of our analysis, are those of the authors and not of the Caltech/MIT Voting Technology Project, nor the foundations supporting this research. Please note that Katz has served as an expert witness in two lawsuits involving voter identification requirements, however the research presented here was neither funded by any interested party to those lawsuits nor discussed in court testimony. 


\section{INTRODUCTION}

That election rules and procedures have been used historically to deny the right to vote to potential participants in democracies is no surprise to any student of elections. There has been a great deal of research showing how election rules and procedures have systematically denied suffrage to women, racial and ethnic minorities, and other groups, especially in the United States (see Kousser 1974; Keyssar 2001 for summaries and analysis). Another line of research on voter participation in the United States has looked at the modern period, and focused on possibly less pernicious, but still potentially problematic, procedures and laws that are argued to make voter registration and turnout more onerous: voter registration deadlines, inaccessible registration and voting processes, and the availability of polling places. This line of research was sparked by the seminal work of Wolfinger and Rosenstone (1978) and their research has been followed by a vast array of studies that mainly focus on the effects of registration laws on voter participation (see Highton 2004 for summaries), though recent research has begun to look directly at how aspects of the voting experience, like the availability of voting machines, might affect participation (e.g., Highton 2006, Mebane 2005).

In recent years, especially in the wake of the disputed 2000 presidential election, there has been much debate about imposing what some see as important safeguards of electoral integrity, but what others see as additional barriers to participation - new requirements for voter identification. The debates about voter identification became central during the legislative maneuvering prior to the passage of the Help America Vote Act (2002), and since passage of HAVA, these arguments have been front and center in the public discussion of election reform. HAVA addressed one aspect of the voter identification debate, as HAVA's Section 303 required that all new registrants must show an identification or provide proof of identification, either with their by-mail application or the first time they show up to vote.

But since the passage of HAVA, many states have pushed for additional identification requirements, in particular, requiring that all voters show identification before they are allowed to obtain and cast a ballot in any election. The justification for the expansion of these identification requirements is to prevent election fraud and to thus improve the integrity of the electoral process, despite some who argue that there is scant evidence that without identification requirements there are significant levels of double voting or voting by non-eligible individuals (Fund 2004; Overton 2006a). As of just prior to the 2006 general election, roughly half of the states required some form of voter identification from all voters (Electionline 2006).

There is little research on the effect that voter identification requirements, of any form, have on the participation of registered voters. Thus, while both HAVA and nearly half of the states have implemented a variety of new identification requirements for voter registration and participation by the 2006 general election, there is little understanding about whether these requirements reduce voter participation, and whether they reduce 
the participation rates of certain classes of voters. This is the central task of our paper: documenting the effect of voter identification requirements on registered voters as they were imposed in states in the 2000 and 2004 presidential elections, and in the 2002 and 2006 midterm elections. Using four election cycles and individual responses to the Current Population Surveys allows us to isolate the effect of voter identification requirements on voter turnout. The state-level panel data allows us to control for changes in the electoral environment both across states and across time - which we could not do with only one year of data - and the individual-level data allows us to answer questions about whether certain sub-populations are disproportionately effected by these regulations - which is not possible using aggregate data. ${ }^{1}$

Looking first at trends in the aggregate data, there is no evidence that voter identification requirements reduce participation. Once we turn to the individual-level data, however, we find that the strictest forms of voter identification requirements - combination requirements of presenting an identification card and positively matching one's signature with a signature either on file or on the identification card, as well as requirements to show picture identification - have a negative impact on the participation of registered voters relative to the weakest requirement, stating one's name. In general, there does not seem to be a discriminatory impact of the requirements on some subpopulations of registered voters, in particular minority registered voters; however we do find evidence that the stricter voter identification requirements do depress turnout to a greater extent for less educated and lower income populations, regardless of race. In the next section we discuss the substantive problem of voter identification requirements in more detail, and the relevant research. We then turn to a discussion of our methodology, the data we use (the 2000-2006 Current Population Survey Voter Supplements, from the U.S. Census Bureau), and our results. Our paper concludes with a discussion of the implications of our work, and with our suggestions for future research.

\section{IDENTIFICATION REQUIREMENTS AND VOTER PARTICIPATION}

Despite much attention in the popular literature, the impact of voter identification requirements on participation in the United States has, to-date, received little academic attention. $^{2}$ For example, in 2005 the Commission on Federal Election Reform, after months of hearings and deliberations, released a report recommending that all voters present photographic identification before they could cast their ballot. But, writing in the Michigan Law Review, Spencer Overton (a member of the Commission, though a member who dissented from the voter photographic identification requirement recom-

\footnotetext{
${ }^{1}$ For methodological specifics and details about the analysis, please see Alvarez, Bailey and Katz (2008).

${ }^{2}$ Recently there has been some controversy regarding a study that the U.S. Election Assistance Commission sponsored regarding voter identification laws, including a study of the effects of voter identification laws on voter participation. We discuss the specifics of the latter study below, and later we compare our results to theirs. Additional information regarding the EAC's voter identification study can be found at http://www.eac.gov/eac_voter_id_fraud.htm.
} 
mendation) noted that there was little research on either the basic rationale for voter photo identification requirements (reducing election fraud) or on the effect of these requirements on voter participation: "Rather than continuing to rely on unsubstantiated factual assumptions, election law scholars and policy-makers should look to empirical data to weight the costs and benefits of various types of election regulations" (Overton 2006b, 681).

Unfortunately, few scholars have so far answered Overton's call for research in this area. We are aware of only a handful of recent studies on this subject. One group of scholars has looked recently at the implementation of voter identification laws, using New Mexico in 2006 as their laboratory (Atkeson et al. 2007; Alvarez, Atkeson and Hall 2007). Despite much debate in New Mexico, in 2006 the voter identification law there allowed a broad range of methods of identifying voters, including a simple written or verbal statement of the voter's basic identifying information (Atkeson et al. 2007). But as these studies have shown, how this was implemented in polling places throughout the state in the 2006 general election varied considerably, and these studies provide evidence that Hispanics were more likely to provide some form of identification than non-Hispanics (Atkeson et al. 2007).

Other scholars have asked whether minority voters are less likely to possess potential forms of identification, than non-minority voters. Barreto, Nuño, and Sanchez (2007) utilize exit polls from the 2006 elections in California, New Mexico, and Washington - all states with signature requirements - to ask voters whether they would be able to provide several different forms of identification, such as a birth certificate or recent bank statement, if required. The study finds that "controlling for age, income, and education, ... immigrant and minority voters are significantly less likely to be able to provide multiple forms of identification" (Barreto, Nuño, and Sanchez 2007, 1).

Another recent study is Lott's analysis of county-level data, for general and primary elections, from 1996 through 2004. His analysis of the aggregated data does not find that voter photo identification requirements in place during this period decreased voter participation rates, noting that "it is still too early to evaluate any possible impact of mandatory photo IDs on U.S. elections" (Lott 2006, 11). Similarly, Milyo (2007) also uses county-level data, but only for the state of Indiana. His study finds no decrease in turnout after the adoption of a photo identification requirement. Further, Milyo (2007) claims that there is an increase in turnout after the adoption of the in those counties with greater percentage of minorities or families in poverty. However, we must be concerned about any claims regarding the impact on particular sub-populations, such as minorities, from any study that uses only aggregate-level data. As is well known, these ecological studies suffer from aggregation bias that can lead to wildly incorrect inferences (see Goodman 1959 and King 1997).

In a different analysis - more like the one we develop and focus on below - Vercellotti and Anderson (2006) analyze the 2004 Current Population Survey's (CPS) Voter Supplement to study the effect of voter identification requirements in the 2004 presidential 
election. Vercellotti and Anderson study both aggregate and individual-level data, and reach a number of conclusions that differ significantly from Lott's analysis. Vercellotti and Anderson find in their aggregate-level analysis that some forms of identification requirements (signature matches and non-photo identification provision) did reduce voter participation, and that in their individual-level analysis of the CPS survey data they found that the deleterious effects of identification requirements were more substantial for non-Whites than for Whites. Their study, however, is methodologically flawed.

Our study is similar to Vercellotti and Anderson's in two ways: first, we employ the same basic data source as they did (the Census CPS Voter Supplement data), and second, we employ a similar theoretical framework. We use the CPS Voter Supplement data for the same reasons as Vercellotti and Anderson: these survey data provide a relatively large sample of the American voting population, sufficiently large so that we can attempt to estimate the effects of voter identification requirements for sub-populations of the electorate (racial and ethnic minorities), and so that we can get variation in the requirements themselves across states. Furthermore, the CPS Voter Supplement data are about as close to a canonical dataset as political scientists have; most of the important studies of political participation, going back to Wolfinger and Rosenstone's seminal contribution (1978) have used the CPS data. ${ }^{3}$ But unlike Vercellotti and Anderson's study, we use a much broader array of CPS Voter Supplement data, from four federal elections, 2000, 2002, 2004, and 2006. By employing four federal elections instead of the single election that Vercellotti and Anderson used we are able to correctly estimate the causal effect of voter identification requirements by utilizing the differences between states that changed their requirements and those that did not. Also with much larger sample sizes we can obtain a much more precise estimate of the effects of voter identification requirements on participation.

In another recent analysis, Mycoff, Wagner, and Wilson (2007) utilize the 2000, 2002, 2004, and 2006 American National Election Studies (NES) to measure the effect of voter identification requirements on turnout in federal elections. Mycoff, Wagner, and Wilson examine both aggregate and individual-level data, and suggest, like Lott, that voter identification requirements have no effect on turnout. Although the authors utilize data from the same four recent federal elections as we do, they analyze each year separately, and in doing so, fail to isolate the causal effect of the institutional change in requirements. Furthermore, as has been noted by others, the CPS data are seen as superior for studying voter turnout, because the NES has much smaller samples and hence much less sample coverage, because the NES has a much lower response rate than the CPS, and the NES post-election interviewing can often run well into December following an election while the

\footnotetext{
${ }^{3}$ There are, of course, exceptions. Like Lott's study cited in the text, there are other aggregate-level studies of voter participation rates, for example, Knack's (2001) study of the effect of the implementation of election-day voter registration on turnout rates across states. Another prominent exception is the study by Verba, Schlozman and Brady (1995), as they collected their own survey data to study civic engagement and participation. But the CPS Voter Supplement data provide extensive cross-sectional data, comparable over time, and thus are well-suited to our analysis. The CPS Voter Supplement data do pose some problems for the study of voter turnout, especially misreporting of voter turnout; this is an issue we return to in our conclusion.
} 
CPS is typically completed in November (Highton 2005). Additionally, the overreporting of turnout in the NES is commonly seen as higher than what the CPS routinely reports. ${ }^{4}$

We use the same theoretical premise as the Vercellotti and Anderson study, and the Mycoff, Wagner, and Wilson study, which is the theoretical basis for most work on voter participation: the cost-benefit calculus of voter turnout articulated in early work on rational choice (Downs 1957; Riker and Ordeshook 1968). The key assumptions of this calculus of voter turnout are that voters are rational, that they are aware of the costs and benefits of participating in an election, and they behave according to the relative comparison of the costs and benefits. Thus, if it is too costly for them to participate - if for example the barriers to participation are high relative to the returns, with the barriers being such things as registration requirements, long lines at polling places, inaccessible voting locations, and other similar factors - they will not cast a ballot on election day. Like these previous two studies, we assume that the more restrictive a state's voter identification requirements, the more likely they are to constitute a hurdle for registered voters, and thus that more restrictive voter identification requirements are likely to be associated with a reduction in the likelihood that an individual registered voter turns out to vote.

It is also instructive to think about how this basic calculus of voting works for different categories of voters, as well. For example, the basic question about whether or not eligible citizens with lower levels of educational attainment are less likely to vote because the barriers to participation, even at the margin, are greater for them than for highly educated voters, has received attention in the research literature (see Wolfinger and Rosenstone 1978; Nagler 1991). But instead of focusing only on the interaction between education and potential barriers to the exercise of the franchise, we are interested below in the interaction between race or ethnicity and barriers to the franchise, especially voter identification requirements. We see this latter interaction as important to study because of the potential legal ramifications of finding that the effects of voter identification requirements are differential across racial or ethnic groups (Overton 2006a), not to mention the normative implications if we find racial or ethnic differences in the effects of voter identification requirements on participation.

Thus, our critical hypotheses, which we test below, flow clearly from the theoretical literature on participation, and are closely linked to decades of applied research on the effects of barriers to voting on participation. First, we hypothesize that where states have imposed more restrictive identification requirements for registered voters, their participation rates should be lower, ceteris paribus, than in states which have less restrictive

\footnotetext{
${ }^{4}$ The U.S. Census Bureau's official report on the 2000 voter supplement data stated: "Significant discrepancies occur each election between the CPS estimates and the official numbers. In the November 2000 CPS, 111 million of the 203 million people of voting age in the civilian noninstitutional population reported that they voted in the 2000 election. Official counts showed 105.6 million votes cast, a difference of about five million votes (5 percent) between the two sources" (U.S. Census Bureau, 2000, page 11). McDonald estimates the NES voter turnout rate in the 2000 presidential election as $72.7 \%$, with his "Reconciled-VAP" turnout rate of $55.2 \%$, that is an overreporting rate of $17.5 \%$ (McDonald 2003; see original data at http://elections.gmu.edu/NES_Bias.htm).
} 
identification requirements for voting. Second, we also hypothesize that these effects of more restrictive voter identification requirements should be stronger for black and Hispanic registered voters than for White eligible voters, ceteris paribus, following arguments that minority voters may be less likely to have appropriate government-issued identification, or that they may be less willing to provide that identification in order to vote (Overton 2006a). Similarly, we hypothesize that the effects of identification requirements on voters with lower levels of education and income will be disproportionately negative.

In the end, while the hypotheses we will test below are similar to those tested by previous scholars, our methodology is much more appropriate for this substantive problem. Our multilevel model combines the approaches of both these previous studies of the 2004 presidential election, but by incorporating data going back to 2000, we are able to better identify and estimate critical parameters in our model, especially the direct effect of voter identification requirements on voter participation, as well as the indirect effects of these requirements on racial minorities, and those on the lower rungs of the socioeconomic scale. Thus, we argue that our framework presents an important contribution over earlier work in this area methodologically, and more importantly, allows us to more confidently answer questions about the potential of voter identification requirements to disenfranchise. In subsequent sections we present our methodological argument in more detail.

\section{VOTER IDENTIFICATION LAWS IN THE STATES}

As a starting point for our analysis, we develop a classification scheme for the different voter identification regimes that exist in the United States. Since the enactment of HAVA, there are eight basic types of requirements to vote at the polls. They are in listed in order of increasing stringency:

1. Voter must state his/her name.

2. Voter must sign his/her name in a poll-book.

3. Voter must sign his/her name in a poll-book and it must match a signature on file.

4. Voter is requested to present proof of identification or voter registration card. ${ }^{5}$

5. Voter must present proof of identification or voter registration card. ${ }^{6}$

6. Voter must present proof of identification and his/her signature must match the signature on the identification provided.

7. Voter is requested to present photo identification. ${ }^{7}$

\footnotetext{
${ }^{5}$ An affidavit may be signed in lieu of presenting identification and a regular (non-provisional) ballot may still be cast.

${ }^{6}$ The range of acceptable proof of identification ranges across the states, but in addition to a form of government-issued photo identification, other acceptable pieces of identification include utility bills, social security cards, student identification cards, paychecks, and bank statements, as well as hunting and fishing licenses and gun permits.

${ }^{7}$ An affidavit may be signed in lieu of presenting photo identification and a regular (non-provisional) ballot may still be cast.
} 
8. Voter is required to present photo identification.

Combinations of the above requirements are often in place, such as requiring a voter to both state and sign his/her name. In our analysis, cases are coded at the level of requirement that is more stringent. In this example, the case would be coded as a signature requirement. Most states in 2004 required that first-time voters who registered by mail to present identification (per HAVA requirements), but here we are interested in the effect of requirements on all registered voters.

Thus, we want to measure the extent to which voter identification requirements affected voter participation at the polls, but this is a difficult methodological problem for several reasons. First, the requirements are not binary. As is apparent from the listing of the types of regimes, it is not the case that a state either requires identification to vote, or does not. States require many different levels of identification from simply stating one's name to showing a picture identification. This further complicates the question, as we must determine not just one effect but several potentially incremental effects. Second, states may differ in their implementation of similar requirements. While one state may consider a student identification card or discount club membership card to be valid photo identification, another state may only recognize government-issued photo identification cards. Third, the data we have to answer this question is relatively sparse. That is, since the changes in voter identification requirements have really only started since the passage of HAVA in 2002 and the law we are most interested in - photo identification requirements - was only implemented in 2006, we have only a small amount of information in the available data about how each type of voter identification requirement might affect participation. Finally, identification requirements are not randomly assigned across states. This is a problem if states with historically lower turnout also tend to adopt stricter identification requirements, then we will have trouble isolating whether the low level of turnout is due to the identification requirement or to other factors that lead a given state to have lower turnout rates.

Figure 1 presents the geographical distribution of voter identification requirements across states over the period 2000 to $2006 .^{8}$ The lightest shade represents the "state name" requirement, while the darkest shade represents the requirement for a photo identification card. In 2000, nine states had the weakest identification requirement, 18 states required a signature to vote, nine states required a matching signature, four states requested an identification card, eight states required an identification card and three states required that the voter's signature match that on the identification card. In 2006, seven states only required voters to state their name at the polls, ten states required a signature, seven states required a matching signature, two optionally required identification, 20 required some form of identification card, three requested a photo identification card and two required that the identification be photo. In Florida, the photo identification allowed ranged from government-issued cards to discount club cards with photos. In

\footnotetext{
${ }^{8}$ In order to save space only the Continental states are included. Alaska required government-issued identification cards in all elections covered here. Hawaii requested identification in 2000 and 2002 , required identification in 2004 and requested photo identification in 2006.
} 

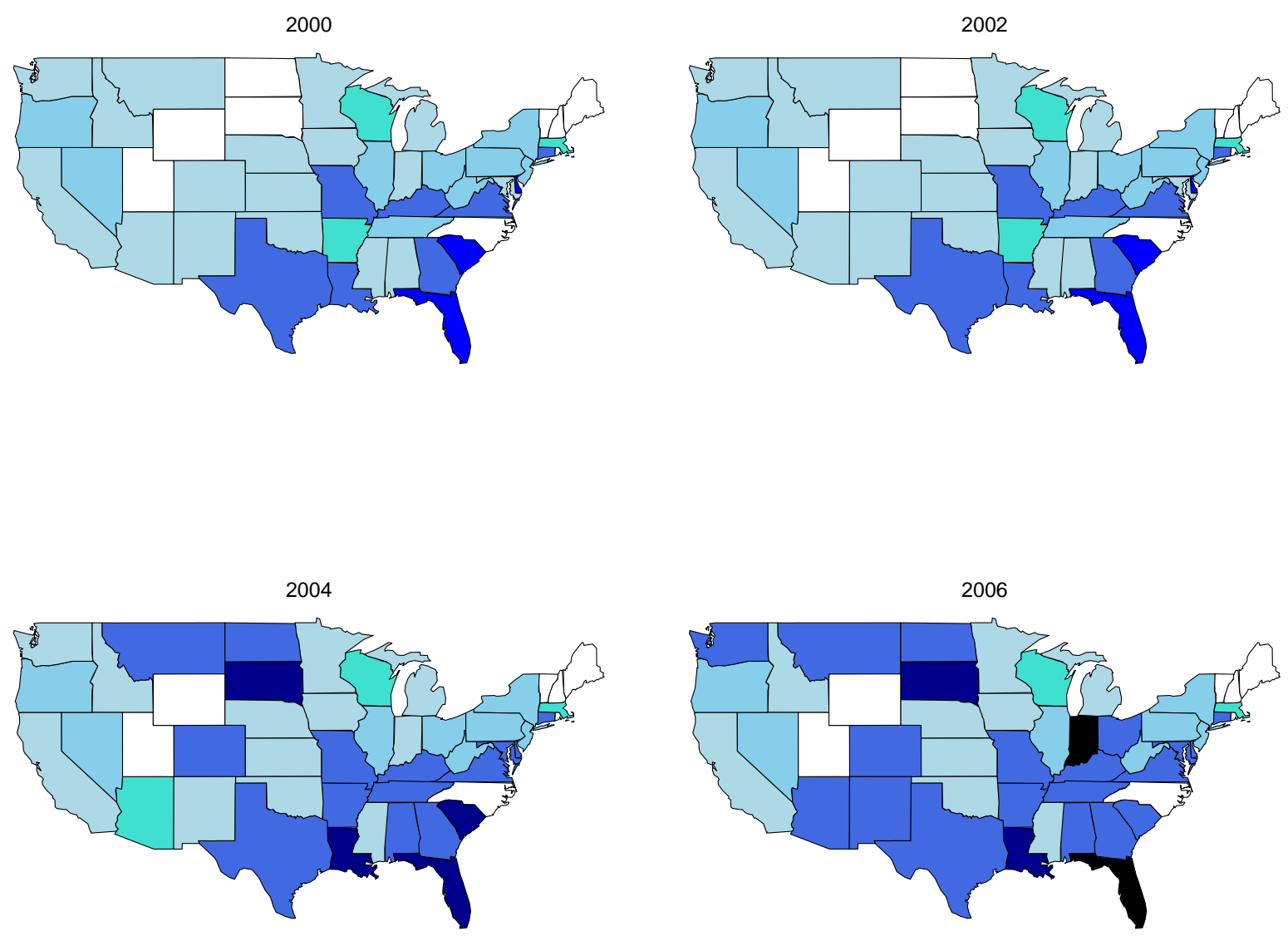

Figure 1: Voter Identification Laws, 2000-2006. Darker shades correspond to more stringent authentication requirements. In general, identification requirements became stricter between 2000 and 2006.

Indiana, only government-issued photo identification and student identification from Indiana state universities were accepted. In addition to the differences between states in any particular year, many states strengthened their identification requirements between 2000 and 2006 and only one state weakened their requirements as can be seen by the darkening of the figure. ${ }^{9}$

The change in requirements over time and across states will allow us to identify and estimate the causal impact of the voter identification requirements. That is, we can compare changes in turnout rates in states that altered their requirements to those

\footnotetext{
${ }^{9}$ South Carolina is the only state to have reduced its requirements during this time frame. It required both an identification card and a matching signature in 2000 and 2002. In 2004, South Carolina requested photo identification, but in 2006 returned to only requiring some form of identification or a voter registration card.
} 


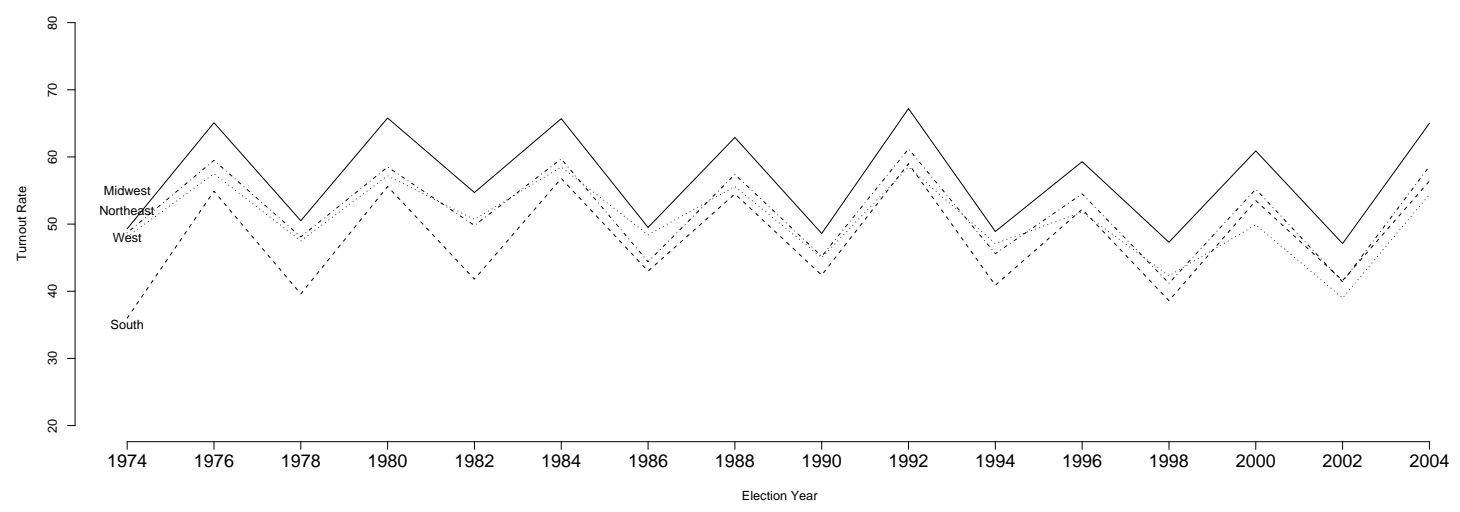

Figure 2: Estimated Turnout of Registered Voters by Region, 1974-2004. Estimates from United States Election Project (http://elections.gmu.edu/).

that did not, and we can attribute any changes to the change in requirements. It is not possible to estimate the causal impact without utilizing both state and temporal variation. Therefore, observation studies using only one state or one year of data can not correctly estimate the casual impact of the adoption of stricter voter identification requirements on turnout.

The critical methodological problem can be see in Figure 1, which clearly shows non-random "treatment assignment" — i.e., states do not randomly choose which voter identification requirement to use. Close examination of the figure shows that states in the Southern and Western regions are more likely than states in the Northeast to have strengthened their voter identification requirements over our study period. As can be seen in Figure 2 turnout in both the South and West is historically lower than that of states in the Northeastern and Midwestern regions. The combination of these two factors in these regions of the United States raises the problem of non-random assignment, an issue that complicates the analysis of the effect of identification requirements on voters.

For example, if we were to look at only 2004, we might conclude that stricter voter identification requirements cause voters to turnout at lower rates because of the correlation between regional turnout rates and likelihood of adopting a more stringent identification requirement. Similarly, if we were to look at one state over time, we might make the same false inferences because of the cyclical turnout rates apparent in the graph. Consider, for example, if we were to compare a state that adopted more stringent requirement in 2002. If we compare 2000 to 2002, we would incorrectly conclude that the decline was caused by the change in identification requirements, but all states saw a drop in turnout because 2002 was a midterm election. Again, this is a critical flaw in earlier studies - by focusing solely on single presidential elections, they are confusing voter identification requirements with other causal factors that cannot be separated in the use 
of only a single election in their analysis. ${ }^{10}$

Our estimation strategy exploits the temporal and geographic variability in voter identification requirements to sidestep the problem on non-random assignment. This is referred to as a difference-in-differences estimator and our analysis is built on a generalization of this procedure. In particular, we use a multilevel model - also referred to as a random effects model - to assess how voter identification requirements affect participation by registered voters, using data from four years of recent CPS Voter Supplement data. While multilevel models have seen many applications in fields outside of political science, only in relatively recent years have we seen the use of multilevel models in political science applications and journals (e.g., Steenbergen and Jones 2002; Raudenbush and Bryk 2002; Western 1998). ${ }^{11}$ The multilevel model allows us to control for the constant factors that cause turnout rates to vary within states and for the cyclical changes in turnout over time.

In addition to using a much richer dataset than previous studies with a generalization of a difference-in-differences estimator to minimize the problem of non-random assignment, we also attempt handle the sparse and ordinal nature of the data. The data is sparse because with eight different types of identification requirements and only fifty states, we do not observe that many elections under a given type of procedure. The standard approach around this problem is to assume some sort of linear (or other parametric) effect. That is, if we consider our list presented at the beginning of the section, we would assume that the effect of a signature match was three times that of merely stating one's name on an individual's probability of voting, since it is third on the list. While the ordering of the list seems plausible, the linear growth (or dose-response curve) is a very strong assumption that seems implausible. We, instead, leverage the ordinal nature of the data to allow for deviations for this linear effect insofar as the data suggest via a Bayesian shrinkage estimator.

In the next section, we present the results from the aggregate component of our multilevel model, examining how voter identification requirements may affect voter participation at the state level. That is followed by a presentation of the results from our individual-level model of participation.

\section{ESTIMATES FROM AGGREGATE LEVEL DATA}

In addition to the unobservable effects on voter turnout, such as regional trends or yearly shocks, we want to control for any observable characteristics that might affect turnout as well. There are two approaches we consider - aggregate and individual-level

\footnotetext{
${ }^{10}$ In general, it is only possible to identify a causal effect in a single cross-section (i.e., one year's data) with random assignment or with an instrumental variable approach (Moffitt 1991).

${ }^{11}$ More recently, a special issue of Political Analysis was devoted to the topic of multilevel modeling in political methodology, with applications to a wide variety of important substantive problems (Kedar and Shively 2005).
} 
data - and our model allows us to consider both levels of data simultaneously. Aggregate data can be a useful source of information about voter turnout mainly because there is no concern that survey respondents are "incorrectly remembering" turning out to vote. We know from surveys that have validated turnout of survey respondents using public voting records, misreporting occurs between five and ten percent of validated cases. ${ }^{12}$ The use of aggregated data to study individual behavior, however, also raises concerns about aggregation bias. That is, it is not be possible to draw conclusions about individual voter's decisions based on solely on the analysis of aggregate data. Further, we are also interested in the impact of these identification requirements on sub-populations, such as racial and ethnic minorities and seniors. Given the coarse nature of state level data, we can not say anything about these populations of interest.

For the aggregate analysis, following the previous literature on turnout, we gathered data on demographic variables at the state-level, such as the percentage of the population who have graduated from high school, the percentage of the population who are minorities, the unemployment rate and per capita income. The specific empirical model of voter identification requirements on state-level turnout rates for this data is:

$$
\ln (\text { turnout rate })=\alpha I D_{s t}+\beta^{0}+\beta^{1} X_{s t}+\epsilon_{s t} ; \quad s=1, \ldots, 51 ; \quad t=1, \ldots, 4 ;
$$

where $s$ indexes states and $t$ indexes years. That is, the logarithm of the turnout rate is a linear function of observable regressors.

The turnout rate is measured relative to registered voters in the state, and the variable of interest, $I D_{s t}$, is coded as an ordinal variable ranging from zero (state name) to seven (photo identification). ${ }^{13}$ The vector of covariates, $X_{s t}$, includes the following:

\% HS Grad: the percent of high school graduates in state $s$ at year $t$, according to the Census Bureau;

Per capita income: the per capita income in state $s$ at year $t$ according to the Bureau of Economic Analysis;

Unemp rate: the unemployment rate in state $s$ at year $t$ according to the Bureau of Economic Analysis;

South: an indicator equal to one if the state is southern and zero otherwise; ${ }^{14}$

$\%$ Non-White: the percent of individuals in state $s$ at year $t$ that are reportedly not White, according to the Census Bureau.

As the level of turnout in a state may vary due to yearly shocks or regional trends

\footnotetext{
${ }^{12}$ There are an array of published studies that have looked at the validated turnout data. See, for example, the early studies by Abramson and Claggett (1984, 1986, 1989, 1991 and 1992), or the more recent analyses by Bernstein, Chadha and Montjoy (2001) or Cassel (2004).

${ }^{13}$ Given the limited amount of state-level observations, it is not possible to do much more than a linear treatment specification. When we turn to the individual level specification with much more data we can relax this assumption.

${ }^{14}$ The states of the South in this study are: Alabama, Arkansas, Florida, Georgia, Louisiana, Mississippi, North Carolina, South Carolina, Texas, and Virginia.
} 


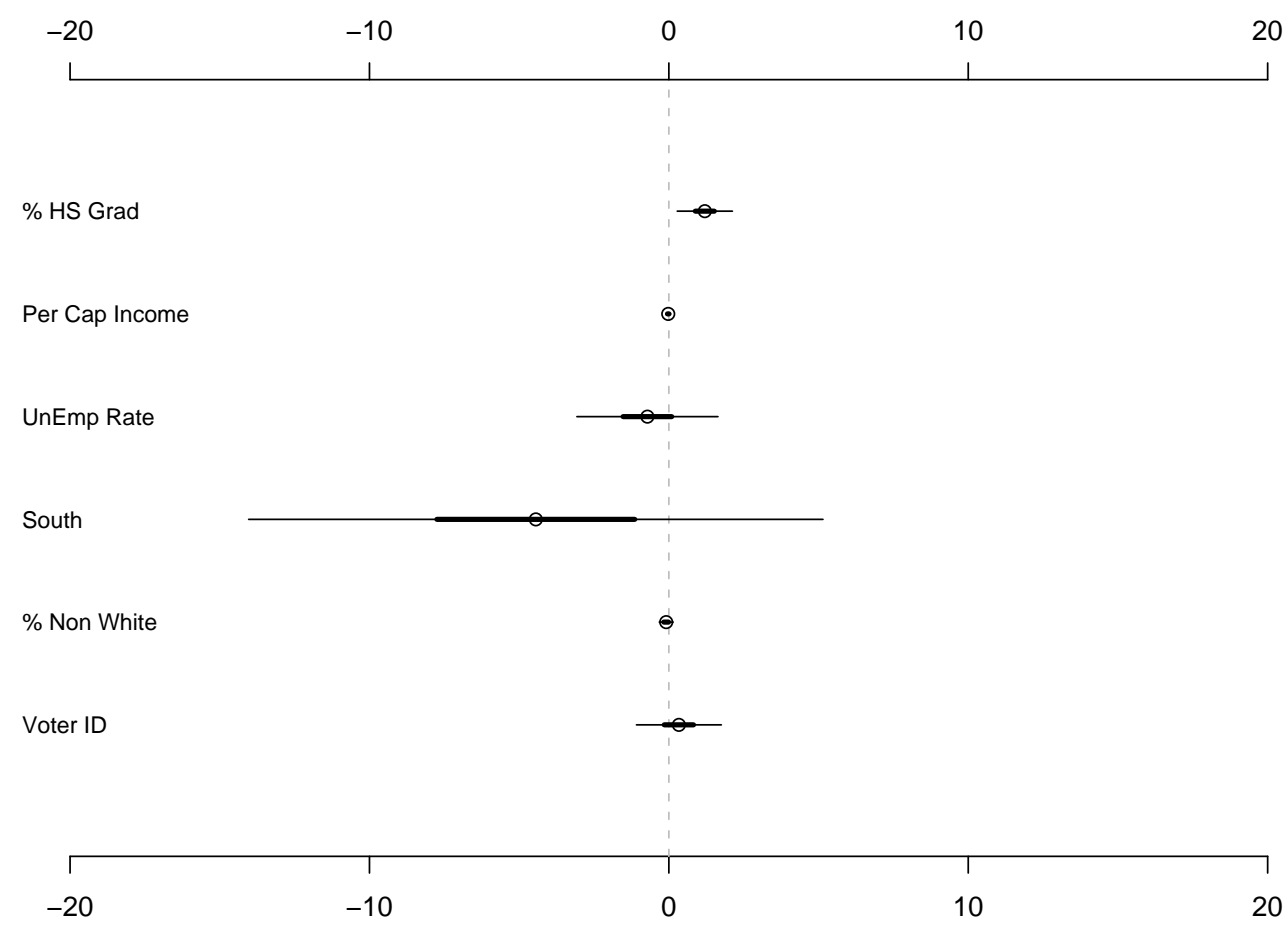

Figure 3: Estimates of the determinants of state level turnout of registered voters, 20002006. The graph shows the result of regression of log(turnout) on the covariates, including state and year effects. The center dots correspond to the point estimates, the thicker lines to the $50 \%$ confidence interval, and the thinner lines to 95\% confidence interval.

(see Figure 2), random effects are included for state and year.

$$
\begin{gathered}
\beta^{0}=\gamma_{s}^{0}+\gamma_{t}^{1} ; \\
\gamma_{s}^{0} \stackrel{\text { iid }}{\sim} N\left(0, \sigma_{\gamma_{s}}\right) ; \\
\gamma_{t}^{0} \stackrel{\mathrm{iid}}{\sim} N\left(0, \sigma_{\gamma_{t}}\right) ; \\
\text { for } s=1, \ldots, S \text { and } t=1, \ldots, T .
\end{gathered}
$$

Our results from the aggregate model can be found in Figure 4. The figure displays the estimated percentage change in turnout among registered voters at the state-level, for voter identification requirements and other contributing factors to aggregate turnout. The circles represent the point estimates, the heavy black lines denote the $50 \%$ confidence interval, and the thin black lines denote the $95 \%$ confidence interval.

As can be seen from the figure, the only state characteristic that has an effect on the rate of turnout in a state is the percentage of high school graduates. As the percentage of high school graduates in a state increases by one unit, the rate of turnout in that 
state increases about two percent. The coefficient on the rate of unemployment has the expected sign — increasing the unemployment rate one point has a negative impact on turnout - but it is not statistically significant. The other variables in the model per capita income, percent of the population non-White, whether the state is in the south, and interestingly voter identification - have no discernible impact on statewide turnout rates. Thus, our analysis of our critical hypothesis at the aggregate level yields no support for the claim that voter identification requirements have any effect on the turnout decisions of registered voters.

\section{ESTIMATES FROM INDIVIDUAL LEVEL DATA}

The aggregate data pose two problems. First, with only 50 states and four years of data, there is very little information available to inform us about the effects of voter identification requirements. Second, answering questions about voter identification laws effects on subgroups is not possible. Because we are most interested in the effect of voter identification laws on individual subgroups of voters - not on state-wide trends - and we would like to be able to more precisely identify these effects, we turn to individual responses from the Current Population Survey in 2000, 2002, 2004 and 2006.

The CPS has a very large sample size (120,000 per year), which affords us good coverage of both states and populations of interest. We do need to worry about overreporting of turnout, an issue we return to in our discussion of future research. In addition to answering questions about voter registration and turnout, respondents to the CPS provide basic demographic information, such as their education level, age, income, sex, and race. Not only do we use these demographic questions to control for varying propensities of turnout based on individual characteristics, we also are able to determine whether voter identification requirements are affecting certain groups disproportionately after controlling for other factors.

As mentioned previously, an additional complication arises because of the non-binary nature of the voter identification requirement. We could not do much about this in the aggregate level model, but with the greater number of respondents in the individuallevel data we have some flexibility estimating the effects of the varying identification requirements. But given the sparseness of the data, precisely estimating individual effects for each of the eight identification requirements is difficult. This would involve coding each voter identification regime as a binary indicator variable in our model, but the concern then is that we simply will have too little information for some of the less-used regimes to identify (let alone precisely estimate) the effects of each voter identification requirement relative to the others. On the other hand, we could assume that the effect is linear across the eight requirements, as we did in the aggregate level model. That is, the effect on the probability that a voter turns out is the same if we change the requirement from stating one's name to signing one's name as if we change the requirement from 
merely requesting a photo identification card to requiring a photo identification card. ${ }^{15}$ This is a strict assumption. As a compromise we, in effect, compute a weighted average these two approaches with the weights being proportional to the amount of information in the data about that particular identification regime. ${ }^{16}$

Specifically, we start with a logistic model of turnout from the CPS. Because we are interested in the effect of identification requirements at the polls and not the various unobserved barriers to voting associated with the registration process, the estimation is conditioned on the subset of respondents who are registered to vote. Our logistic model takes the form:

$$
\begin{gathered}
\operatorname{Pr}\left(Y_{i t}=1\right)=\operatorname{logit}^{-1}\left(\alpha_{j[i]}+\beta^{0}+\beta^{1} X_{i t}\right), \\
\text { for } j=1, \ldots, 8 ; \quad i=1, \ldots, N ; \text { and } t=1, \ldots, 4 ;
\end{gathered}
$$

where $j$ indexes identification regime, $i$ indexes the respondents, and $t$ indexes years. The variable $Y_{i t}$ is binary and equal to one if the respondent reported voting in that year's election. The variable $\beta^{0}$ is an intercept term. The vector of covariates, $X_{i t}$, includes the following:

South: an indicator equal to unity if the respondent resides in a southern state;

Female: an indicator equal to unity if the respondent is female;

Education: a ordinal variable indicating the reported level of education — 'some high school,' 'high school graduate,' 'some college,' or 'college graduate';

Education ${ }^{2}$ : the squared value of Education;

Age: the respondent's age in years;

$A g e^{2}$ : the squared value of $A g e$;

Income: an ordinal variable indicating the reported level of household family income that takes on 13 values - ranging from 'Less than $\$ 5,000$ ' to 'More than $\$ 75,000$ '; Non-White: an indicator equal to unity if the respondent reported a race other than

White.

This covariate vector replicates what we consider to the be canonical model of voter turnout in the literature that uses CPS Voter Supplement data (e.g., Nagler 1991).

As the level of turnout in a state may vary due to yearly shocks or regional trends, random effects are included for state and year.

$$
\begin{gathered}
\beta^{0}=\gamma_{s[i]}^{0}+\gamma_{t[i]}^{1} ; \\
\gamma_{s[i]}^{0} \stackrel{\text { iid }}{\sim} N\left(0, \sigma_{\gamma_{s}}\right) ; \\
\gamma_{t[i]}^{0} \stackrel{\text { iid }}{\sim} N\left(0, \sigma_{\gamma_{t}}\right) ; \\
\text { for } s=1, \ldots, S \text { and } t=1, \ldots, T .
\end{gathered}
$$

\footnotetext{
${ }^{15}$ Recall that requesting a photo identification card allows the voter the option of signing an affidavit swearing their identity and then casting a regular ballot, whereas requiring a photo ID only allows the voter the option of casting a provisional ballot.

${ }^{16}$ The particular analysis we use, a Bayesian shrinkage estimator, is documented in Alvarez, Bailey and Katz (2008).
} 


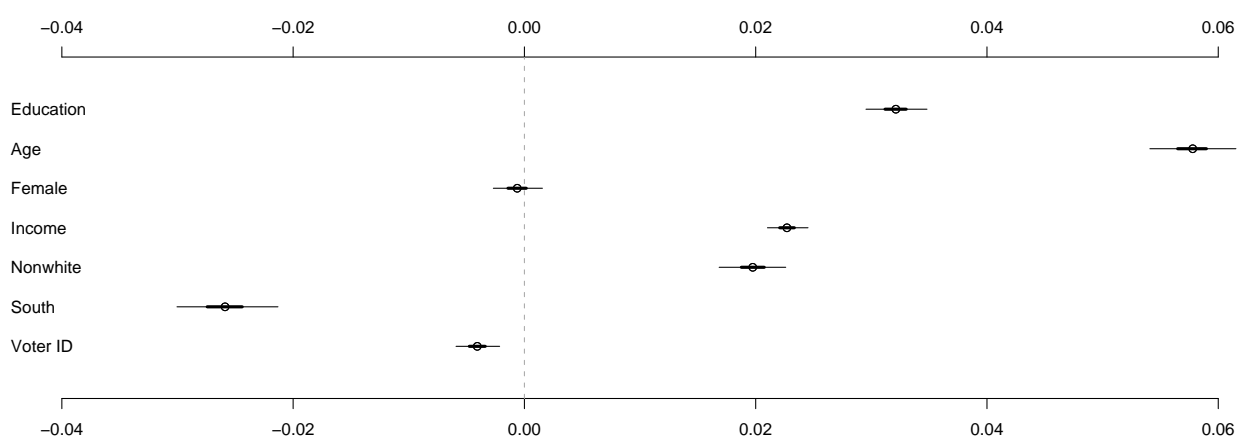

Figure 4: Estimates of the determinants of individual level turnout of registered voters, 2000-2006. The graph shows the result of logistic regression of the probability of voting on the covariates, including state and year effects. The center dots correspond to the point estimates, the thicker lines to the 50\% confidence interval, and the thinner lines to $95 \%$ confidence interval.

That is, each individual $i$ in state $s$ and year $t$ share a common intercept term, with each level of intercepts pooled toward zero and with common variance.

As noted above, we could model the impact of the variable of interest, $I D$, as an unpooled additive effect (e.g., indicator variables for each regime), or alternatively, constrain the effect to be linear. Rather than commit to either extreme, we effectively combine the first two approaches into a sort of weighted average, where the weighting variable is determined by the data:

$$
\begin{gathered}
\alpha_{j[i]}=\alpha^{0}+\alpha^{1} I D_{i t}+\nu_{j}, \\
\nu_{j} \stackrel{\mathrm{iid}}{\sim} N\left(0, \sigma_{\alpha}\right) .
\end{gathered}
$$

That is, for each identification requirement level, $j$, the estimated impact on turnout is a random intercept term, $\nu_{j}$, and is pooled toward a group linear impact, $\alpha^{0}+\alpha^{1} I D_{i t} \cdot{ }^{17}$

Our results for the individual model can be found in Figure 5. The figure displays the estimated percentage change in the probability of turning out to vote, conditional upon being registered, for voter identification requirements and demographic control variables. The circles represent the point estimates, the heavy black lines denote the $50 \%$ confidence interval, and the thin black lines denote the $95 \%$ confidence interval.

Living in the South decreases the odds that an individual in our sample votes, while being older, more educated and wealthier increases the odds an individual turns out to

\footnotetext{
${ }^{17} \mathrm{~A}$ final consideration in the third model is interpretation of the $\alpha^{0}$ and $\alpha^{1}$ parameters. These parameters are partially unidentified between the linear trend in the $\nu_{j}$ parameters. The identification is partial, as the $\nu_{j}$ parameters are pooled toward zero, but with only $J=8$ groups, converging the algorithm is time consuming. To correct for this problem, after estimation, the data is "post-processed" to obtain finite population slope parameters based on the regression of $\alpha_{j}$ on $I D_{j}$. This is equivalent to constraining the $\nu_{j}$ parameters to have mean zero and slope zero (Gelman and Hill, 2006).
} 
vote. In our sample, being female does not effect the probability of voting, but being a minority increases the probability of turning out to vote, conditional on being registered to vote. These effects are all consistent with the previous literature on turnout, lending credence to our model's specification (e.g., Nagler 1991). Increasing the strength of voter identification requirements, on average, decreases the probability of turning out to vote. We examine the deviations from this linear trend below.

Figure 5 plots the average marginal effect of voter identification regimes on the probability that a respondent turns out to vote. The horizontal axis represents the voter identification requirements. The vertical axis plots the probability of turning out to vote. We note that the estimated probabilities are high, but recall we are looking at registered voter only and not eligible citizens, as is often done. Turnout rates about among eligible citizens is well below a half in recent elections, but in our sample of registered voters nearly $80 \%$ report turning out to vote. The line represents the probability of voting for a mean respondent in our sample, for each identification requirement being in place. The points on the graph denote the deviation from the linear trend estimated for each requirement and the vertical bars denote the $95 \%$ intervals of uncertainty around each. Interestingly, we see that the requirements for signature matching, requiring an identification card and requiring a photo identification card have a more negative effect on participation than suggested by the simple linear model. Requesting identification cards and requesting photo identification cards is less strict than suggested by the linear trend. These estimates first indicate that indeed, voter identification requirements do not have a simple linear effect on the likelihood that a voter participates. In addition, we see that the stricter requirements - requirements more than merely presenting a non-photo identification card - are significant negative burdens on voters, relative to a weaker requirement, such as merely signing a poll-book.

Previous studies that we are aware of, however, did not use multiple election cycles in their analysis; thus those studies have likely confused the possible effects of new voter identification requirements with the cross-sectional correlations we discussed earlier. Recall in Figures1 and 2 we showed that states with low turnout were also states which had imposed strict voter identification requirements in 2004. Here, as we have data that varies by state and time, we are able to separately identify and estimate the effects of voter identification requirements on voter turnout, that is, separately from the confounding effects of past voter participation rates and voter identification regimes.

Next, we turn to the critical question of the possible interaction between the various voter identification regimes and the racial identify of registered voters in the CPS samples: do voter identification requirements, especially the stricter ones, depress the likelihood of turnout more for non-White registered voters than for White registered voters? To answer this question, we estimated a slight variant of the model used above, which includes interaction terms for voter identification requirements and the racial identity of the voters in the CPS samples. This model includes both the shrinkage estimator and in our linear term an interaction between the voter identification regimes and the racial identify of each registered voter. These results from this analysis are given in Figure 6. 


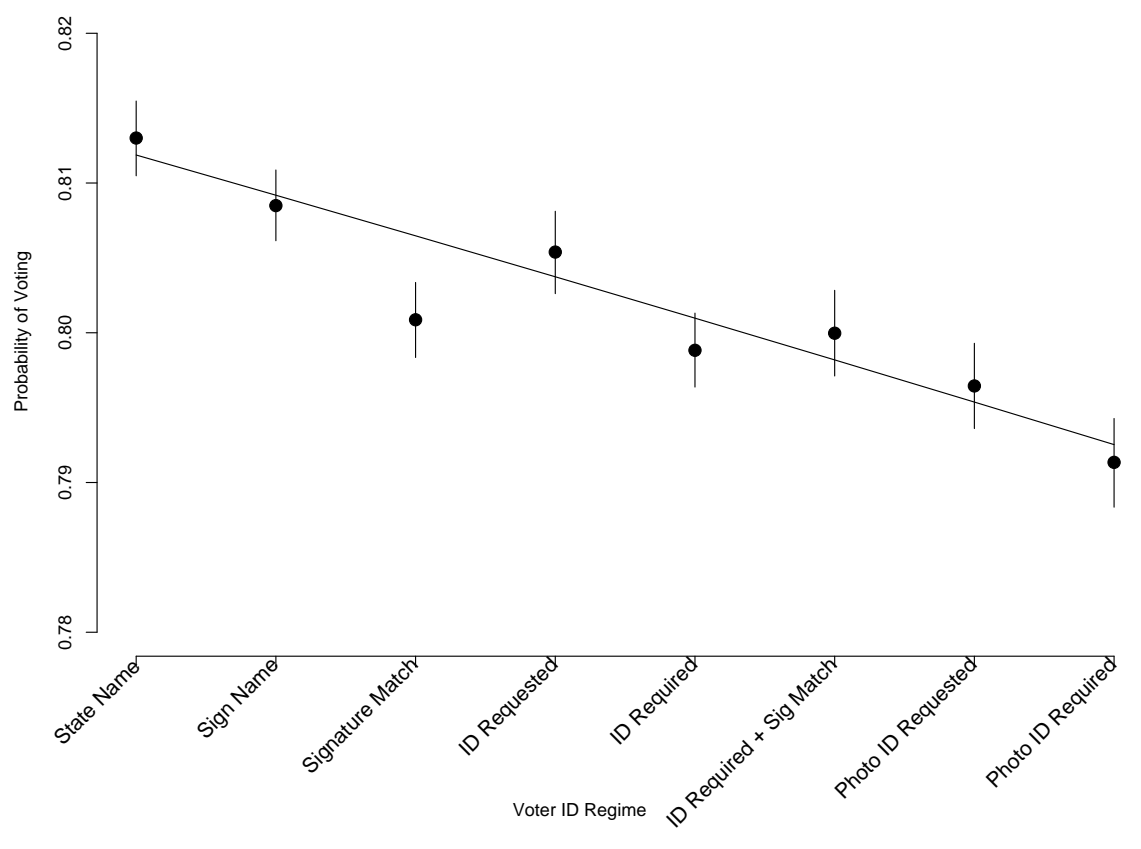

Figure 5: Average estimated probability of voting by identification requirement. The graph plots the average impact from our sample of registered voters from the Current Population Survey (2000-2006). The estimates come from a logistic regression of the probability of voting controlling for demographic characteristics. The solid line is the linear trend that the identification effects are shrunk towards. The dots are the point estimates and the bars represent the $95 \%$ confidence intervals for the effect.

In the left panel we give the results of the voter identification regimes for White registered voters, and in the right panel of Figure 6 the results for non-White registered voters. It is clear from comparison of the two graphs that we can reject the hypothesis that there is a substantial racial difference in the impact of voter identification requirements. First off, we see that the slopes differ in the two panels, and in fact, the line for White registered voters is more strongly negative than for non-White registered voters. Also, when we look at some of the specific regimes, especially the most restrictive ones, our analysis here indicates that they have a more strongly negative effect on the participation of White, relative to non-White voters, all other variables held constant in our model. This is an important result. Controlling for the factors usually seen in models of voter participation, especially education and income, we see no evidence that strict voter identification requirements are racially discriminatory.

We note that not controlling for socioeconomic status in our analysis would likely show a "significant", but incorrect, racial effect since race is highly, but not perfectly correlated with socioeconomic status. ${ }^{18}$ As a matter of good statistical practice to estimate a causal

\footnotetext{
${ }^{18}$ More formally, if one does a principal component analysis between race, eduction, and income from
} 

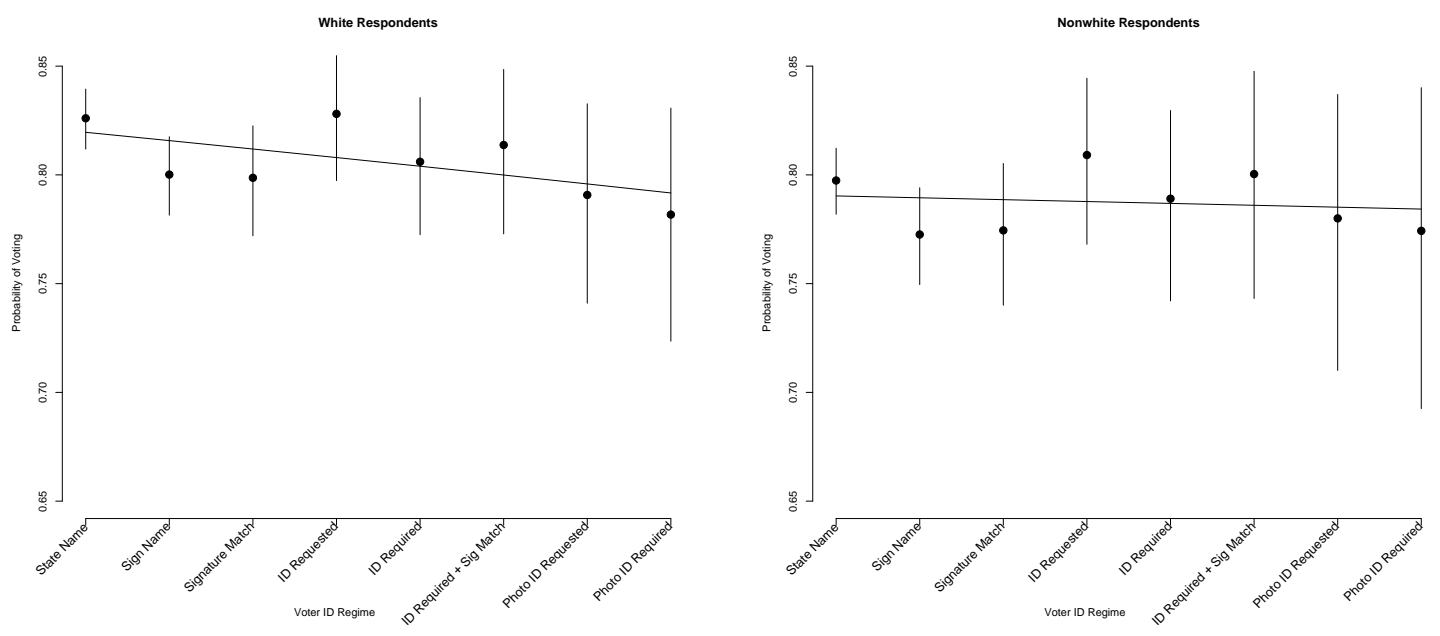

Figure 6: Estimated probability of voting by identification requirement and race. The graphs plot the impact for an average registered voter from the Current Population Survey (2000-2006) for Whites and Non-Whites. The estimates come from a logistic regression of the probability of voting controlling for demographic characteristics. The solid line is the linear trend that the identification effects are shrunk towards. The dots are the point estimates and the bars represent the $95 \%$ confidence intervals for the effect.

impact in observational studies, we need to control for observable factors that we know alter the probability of voting. Further, we are able to independently estimate the impact of race because in the CPS sample there are both low socioeconomic status Whites and high socioeconomic status non-Whites. What the estimator is doing is looking at a fixed socioeconomic level and comparing the probability of voting under different voter identification policies to see if White and non-White registered voters turnout at different rates.

Next we turn to three other important socio-demographic variables in our turnout model: education, age and income. We are interested here in seeing whether these variables have any interactive effect with identification requirements. In particular, there is reason to believe that registered voters who are of lower educational attainment, lower income, or who are younger may be more likely to be deterred from voting as identification requirements increase. These next figures plot the probability of voting conditional on being a mean respondent under each identification regime, tracing out the likelihood for voting as education, age, and income levels vary. The estimated models include an interaction term between the demographic variable of interest and identification type. The dashed lines are the confidence intervals for the random effects term only, and do not include the uncertainty in the estimate; these are provided for convenience only and should not be used for direct inference.

our data, only one of the eigenvalues has an absolute value greater than one, suggesting that there is only one underlying dimension being tapped by these three variables. 
Beginning with the interactive effect between voter identification regime and educational attainment in Figure 7, we see that there is a slight, but significant, interaction between these two variables, controlling for everything else in our model. As we move from the less to more restrictive voter identification requirements, we do see that registered voters at the lower end of the educational attainment scale are less likely to participate. For example, in states that require only that a registered voter provide their name, or sign their names, relative to states that require that a registered voter produce a photographic identification, registered voters with only some high school are significantly less like to vote, whether the registered voter is White or non-White.

Next, in Figure 8, we see little interaction between voter identification requirements and age. In particular, we expected to see that younger voters would be significantly less likely to vote in states with more restrictive identification regimes in place; we see little evidence in this figure to support that hypothesis. Nor do we see older voters being deterred more.

Finally, we show the interaction between the other measure of socioeconomic status and voter identification regimes in Figure 9. The various panels show the different voter identification regime effects for the various levels of household family income. As we have seen in the graph in Figure 7 for education, we do see evidence of an interactive effect, even after controlling for all of the other variables in our model. This is not surprising given that household income and education levels are highly correlated. As expected, voters with lower levels of income are less likely to vote under the more restrictive voter identification regimes; comparing again the extremes of states that simply require the voter provide their name, to those states that require a photographic identification from the registered voter in order to cast a ballot, we see that lower income registered voters in both racial categories in the latter type of state are significantly less likely to vote.

In conclusion, our analysis of the individual-level component of our multi-year and multilevel model, we have found a number of significant results. First, we see that there is evidence to support the claim that the most restrictive forms of voter identification requirements do lead to lower levels of participation by registered voters. However, we find no evidence to support the hypothesis that this effect is more profound for nonWhite registered voters, controlling for other variables, especially income and education. Yet we find that these other socioeconomic status variables, especially education and income, do show a significant interactive effect with stricter identification requirements. In particular, we find that registered voters with low levels of educational attainment or lower levels of income of all racial/ethnic groups are less likely to vote the more restrictive the voter identification regime.

\section{DISCUSSION}

In general, there is scant research on the effect that voter identification requirements, of any form, have on the participation of registered voters. In an attempt to understand 

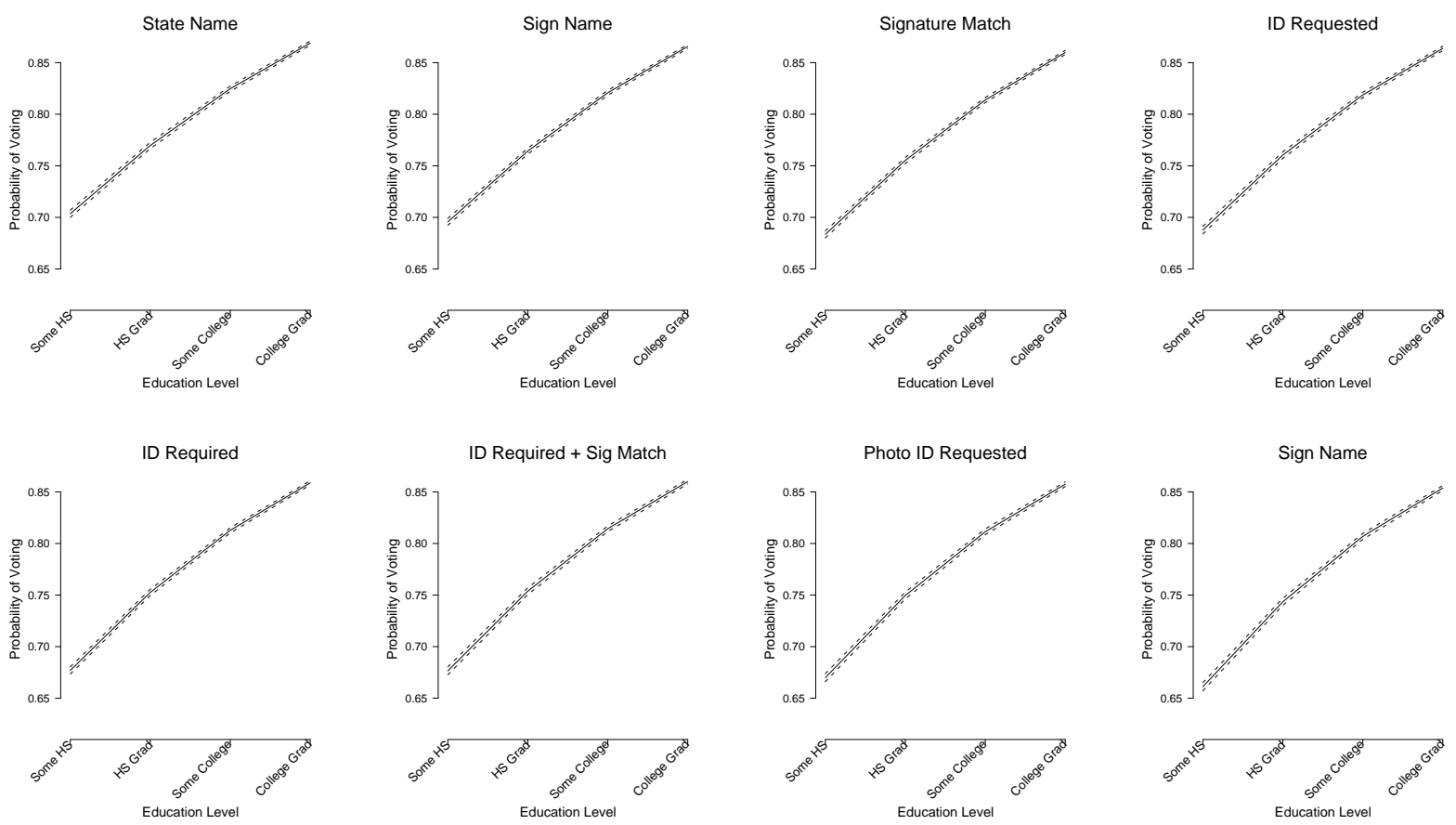

Figure 7: Estimated probability of voting by identification requirement and education level. The graphs plot the average estimated probability of voting by registered voter respondent from the Current Population Survey (2000-2006) given different voter identification regimes as education levels vary. The estimates come from a logistic regression of the probability of voting controlling for demographic characteristics. The dashed lines are the confidence intervals for the random effects term only, and do not include the uncertainty in the estimate; these are provided for convenience only.

whether the requirements imposed by both HAVA and nearly half the states reduce registered voter participation, we used a novel methodology to study the effects of voter identification requirements on the likelihood that voters participate in these two presidential elections, a multilevel binary logit model that allows us to appropriately model how covariates from both the individual and state level, and their interaction, affect the decision to participate (Gelman and Hill 2006). In addition, we use a random effects model of the ordinal voter identification treatment variable, a substantially better specification of this important variable relative to other studies. By combining these two approaches we are able to simultaneously get the most out of sparse data to answer important policy questions, particularly about subgroups, and to address concerns about properly modeling the ordinal treatment variable. We find no evidence that voter identification requirements reduce participation at the aggregate level. At the individual level, voter identification requirements of the strictest forms - combination requirements of presenting identification and matching signatures, as well as photo identification requirements - have a negative impact on voter participation relative to the weakest requirement of stating one's name. In general, there does not seem to be a discriminatory impact of the requirements for some subgroups, such as non-White registered voters. However, we 

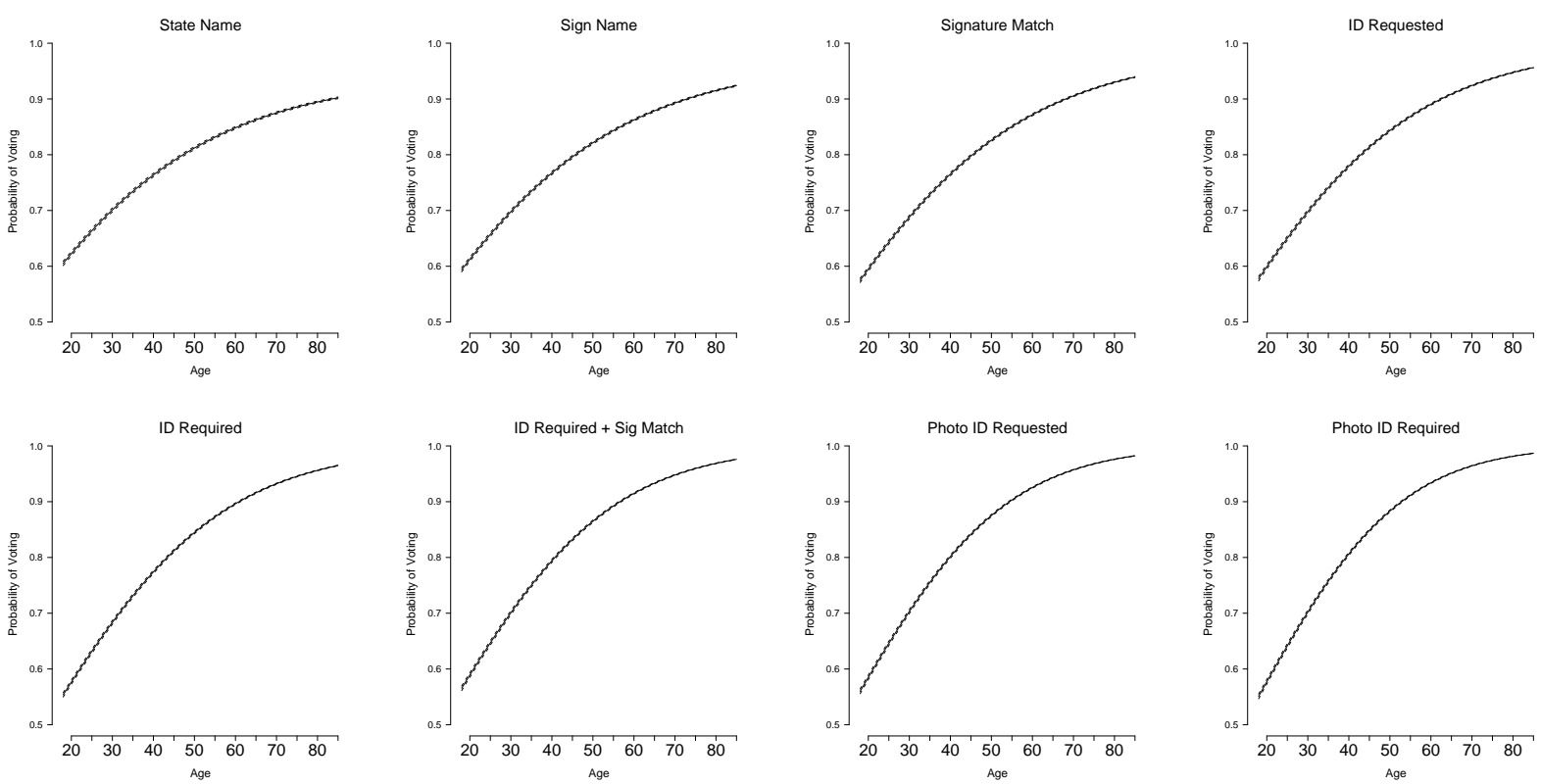

Figure 8: Estimated probability of voting by identification requirement and age. The graphs plot the average estimated probability of voting by registered voter respondent from the Current Population Survey (2000-2006) given different voter identification regimes as education levels vary. The estimates come from a logistic regression of the probability of voting controlling for demographic characteristics. The dashed lines are the confidence intervals for the random effects term only, and do not include the uncertainty in the estimate; these are provided for convenience only.

do find that for registered voters with lower levels of educational attainment or lower income, stricter voter identification requirements do lead to lower turnout, for voters of all races.

Further research is necessary, however, as there is little information in the current data on photo identification requirements - and only with the passage of time will we build up larger databases with more information on the behavior of registered voters in states with different voter identification requirements. Our analysis, using all of the available CPS Voter Supplement data from 2000 through 2006, demonstrates the methodological and substantive importance of examining how voter identification requirements affect voter behavior, as some states move to implement new voter identification requirements and others do not. Additionally, our methodological innovation in this paper, utilizing a multilevel model to study voter participation, is an important advance in the field. While our focus here has been on a new substantive problem, our model did provide important new estimates for the canonical questions about voter participation that have existed in the research literature for the past few decades. We believe that this multilevel approach towards studying the question of voter participation, as well as many other questions of voting behavior that involve data measured at multiple levels, will represent an important advance in the study of this important substantive question. 

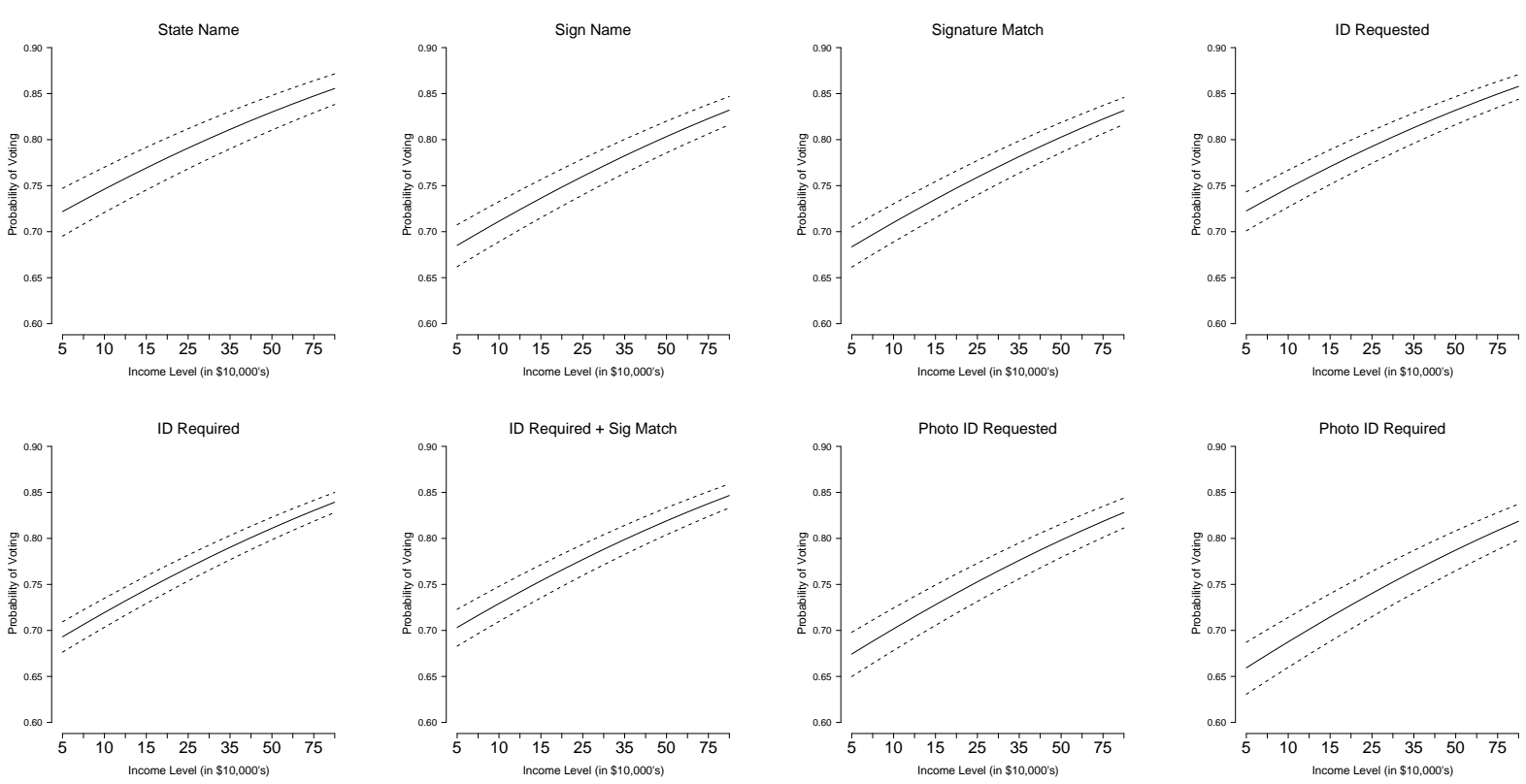

Figure 9: Estimated probability of voting by identification requirement and income level. The graphs plot the average estimated probability of voting by registered voter respondent from the Current Population Survey (2000-2006) given different voter identification regimes as education levels vary. The estimates come from a logistic regression of the probability of voting controlling for demographic characteristics. The dashed lines are the confidence intervals for the random effects term only, and do not include the uncertainty in the estimate; these are provided for convenience only.

However, one methodological issue will need to be addressed in the next round of our research, and that will be to incorporate a correction in the model for the misreporting of turnout. While the misreporting of turnout in the CPS Voter Supplement is not as severe as that noted for other surveys of voter behavior (for example, the American National Election Survey as studied in past research, e.g., Burden 2000). The 2004 CPS Voter Supplement reports a discrepancy of $3 \%$ between the CPS estimate of turnout and the official count of the Clerk of the House of Representatives; historically, the disparity has ranged between 4 and $12 \% .{ }^{19}$ Given that research has shown that misreporting of turnout is systematically related to demographic attributes like education, and also varies by race and ethnicity, clearly adjusting for misreporting of turnout in models of participation is an important methodological step towards obtaining consistent estimates of how factors like identification requirements affect turnout. ${ }^{20}$

Finally, we need to bring other data to bear as we seek to answer research questions

\footnotetext{
${ }^{19}$ See the report of the U.S. Census Bureau, "Voting and Registration in the Election of November 2004", PS 20-556, March 2006, http://www.census.gov/prod/2006pubs/p20-556.pdf.

${ }^{20} \mathrm{As}$ we noted earlier, there has been much research on the attributes of voters who misreport turnout, for example Abramson and Claggett 1984, 1986, and 1991; Bernstein, Chadha and Montjoy 2001; Claussen 1968; Hill and Hurley 1984; Katosh and Traugott 1981; Sigelman 1982; Silver, Anderson and Abramson 1986; Traugott and Katosh 1979.
} 
regarding voter identification laws. Our analysis, and others like it using CPS Voter Supplement data, focuses on what we know of voter identification laws across states and how those laws, if implemented as written, might influence the behavior of registered voters. We cannot not easily study, however, the extent to which these laws are not being implemented as written; for example, it might be the case that in some places registered voters (or just some registered voters) are being asked to provide photographic identification when they try to vote, when that is not current state law, or that in other places registered voters (or again just some registered voters) are not being asked for identification when that should be required under state law. Additional research should focus on implementation of voter identification laws, both in states with such requirements and those without, to determine the extent to which they are being correctly applied, and if incorrectly applied, whether that is affecting the ability of potential voters to exercise their franchise effectively (Alvarez, Atkeson and Hall, 2007; Atkeson et al. 2007). Furthermore, future research should also look at the requirement identifications now in place, as required by HAVA, and whether those additional identification requirements are imposing additional hurdles for eligible citizens as they seek to register to vote.

\section{REFERENCES}

Abramson, Paul and William Claggett. 1984. "Race-Related Differences in Self-Reported and Validated Turnout." Journal of Politics 46, 719-738.

Abramson, Paul and William Claggett. 1986. "Race-Related Differences in Self-Reported and Validated Turnout in 1984." Journal of Politics 48, 412-422.

Abramson, Paul and William Claggett. 1989. "Race-Related Differences in Self-Reported and Validated Turnout in 1986." Journal of Politics 51, 397-408.

Abramson, Paul and William Claggett. 1991. "Race-Related Differences in Self-Reported and Validated Turnout in the 1988 Presidential Election." Journal of Politics 53, 186-197.

Abramson, Paul and William Claggett. 1992. "The Quality of Record Keeping and Racial Differences in Validated Turnout." Journal of Politics 54, 871-880.

Alvarez, R. Michael, Lonna Rae Atkeson and Thad E. Hall, principal authors. 2007. "The New Mexico Election Administration Report: The 2006 November General Election." http://vote.caltech.edu/reports/NM_Election_Report_8-07.pdf.

Alvarez, R. Michael, Delia Bailey and Jonathan N. Katz. 2008. "The Effect of Voter Identification Laws on Turnout: A Note on the Estimation of Ordinal Treatment Effects." Manuscript, California Institute of Technology and Washington University in St. Louis.

Alvarez, R. Michael, Thad E. Hall, and Betsy Sinclair. 2007. "Katrina's Voters: Floods and Representation." Paper presented at the 2007 Annual Meetings of the Midwest Political Science Association. 
Atkeson, Lonna Rae, Lisa A. Bryant, Thad E. Hall, Kyle L. Saunders and R. Michael Alvarez. 2007. "New Barriers to Participation: Application of New Mexico's Voter Identification Law." Paper presented at the 2007 Annual Meeting of the American Political Science Association, Chicago, Illinois.

Barreto, Matt A., Stephen A. Nuño, and Gabriel R. Sanchez. 2007. "Voter ID Requirements and the Disenfranchisements of Latino, Black and Asian Voters." Paper presented at the 2007 Annual Meeting of the American Political Science Association, Chicago, Illinois.

Bernstein, Robert, Anita Chadha, and Robert Montjoy. 2001. "Overreporting Voting: Why it Happens and Why it Matters." Public Opinion Quarterly 65, 22-44.

Burden, Barry C. 2001. "Voter Turnout and the National Election Studies." Political Analysis 8, 4, 389-398.

Cassel, Carol A. 2004. "Voting Records and Validated Voting Studies." Public Opinion Quarterly 68, 102-108.

Clausen, Aage. 1968. "Response Validity: Vote Report." Public Opinion Quarterly 32, 588-606.

Downs, Anthony. 1957. An Economic Theory of Democracy. New York: Harper Collins.

Electionline, 2002. "Election Reform Briefing: Voter Identification." http://electionline. org/Portals/1/Publications/Voter\%20Identification.pdf

Electionline, 2004. "Election Preview 2004: What's Changed, What Hasn't and Why." http://electionline.org/Portals/1/Publications/Election.preview . 2004. report.final.update.pdf

Electionline, 2006. "Election Reform Briefing 15: The 2006 Election." http://www . electionline.org/Portals/1/Publications/EB15.briefing.pdf

Fund, John. 2004. Stealing Elections: How Voter Fraud Threatens Our Democracy. New York: Encounter Books.

Gelman, Andrew and Jennifer Hill. 2006. Data Analysis Using Regression and Multilevel/Hierarchical Models. New York: Cambridge University Press.

Goodman, Leo 1959. "Some Alternatives to Ecological Correlation." American Journal of Sociology 64:610-625.

Highton, Benjamin. 2004. "Voter Registration and Turnout in the United States." Perspectives on Politics 2, 507-515.

Highton, Benjamin. 2005. "Self-Reported versus Proxy-Reported Voter Turnout in the Current Population Survey." Public Opinion Quarterly 69, 113-123. 
Highton, Benjamin. 2006. "Long Lines, Voting Machine Availability, and Turnout: The Case of Franklin County, Ohio in the 2004 Presidential Election." PS: Political Science and Politics 39, 1, 65-68.

Hill, Kim and Patricia Hurley. 1984. "Nonvoters in Voters' Clothing: The Impact of Voting Behavior Misreporting on Voting Behavior Research." Social Science Quarterly 65, 199-206.

Katosh, John and Michael Traugott. 1981. "The Consequences of Validated and SelfReported Voting Measures." Public Opinion Quarterly 45, 519-535.

Kedar, Orit and W. Phillips Shively. 2005. "Introduction to the Special Issue." Political Analysis 13, 4, 297-300.

Keyssar, Alexander. 2001. The Right to Vote: The Contested History of Democracy in the United States. New York: Basic Books.

King, Gary. 1997. A Solution to the Ecological Inference Problem. Princeton, NJ: Princeton University Press.

Kousser, Morgan. 1974. The Shaping of Southern Politics: Suffrage Restriction and the Establishment of the One-Party South, 1880-1910. New Haven: Yale University Press.

Knack, Stephen. 2001. "Election-day Registration: The Second Wave." American Politics Research 29, 65-78.

Lott, John R. 2006. "Evidence of Voter Fraud and the Impact that Regulations to Reduce Fraud Have on Voter Participation Rates." Available at SSRN: http: //ssrn. com/abstract $=925611$.

McDonald, Michael P. 2003. "On the Over-Report Bias of the National Election Studies Turnout Rate." Political Analysis 11, 180-186.

Mebane, Walter R., Jr. 2005. "Voting Machine Allocation in Franklin County, Ohio, 2004: Response to U.S. Department of Justice Letter of June 29, 2005." http: //macht.arts. cornell. edu/wrm1/franklin2.pdf.

Milyo, Jeffrey. 2007. "The Effects of Photographic Identification on Voter Turnout in Indiana: A County-Level Analysis.(Revised December 2007)" Institute of Public Policy, University of Missouri, Report 10-2007. http://web.missouri.edu/ 〜milyoj/files/Report\%2010-2007\%20revised.pdf

Moffit, Robert. 1991. "Program Evaluation with Nonexperimental data." Evaluation Review 15, 291-314.

Mycoff, Jason D., Michael Wagner, and David Wilson. 2007. "The Effect of Voter Identification Laws on Turnout." Paper presented at the 2007 Annual Meeting of the American Political Science Association. 
Nagler, Jonathan. 1991. "The Effect of Voter Registration Laws and Education on U.S. Voter Turnout." American Political Science Review 85, 1393-1405.

National Association of Secretaries of State. 2003. "Voter Identification Requirements by State." Survey. http://www . nass .org/index . php?option=com_docman\&task= doc_download\&gid=80.

National Commission on Election Reform. 2002. To Ensure Pride and Confidence in the Electoral Process: Report of the National Commission on Election Reform. Washington, D.C.: Brookings Institution Press.

Overton, Spencer. 2006a. Stealing Democracy: The New Politics of Voter Suppression, New York: W.W. Norton.

Overton, Spencer. 2006b. "Voter Identification." Michigan Law Review, forthcoming, v. 105. http://docs. law/gwu.edu/facweb/soverton/voteridentification.pdf .

Raudenbush, Stephen W. and Anthony S. Bryk. 2002. Hierarchical Linear Models: Applications and Data Analysis Methods, 2nd. edition. Newbury Park: Sage.

Riker, William H. and Peter C. Ordeshook. 1968. "A Theory of the Calculus of Voting." American Political Science Review 62, 25-42.

Sigelman, Lee. 1982. "The Nonvoting Voter in Voting Research." American Journal of Political Science 26, 47-56.

Silver, Brian, Barbara Anderson, and Paul Abramson. 1986. "Who Overreports Voting?" American Political Science Review 80, 613-624.

Steenbergen, Marco R. and Bradford S. Jones. 2002. "Modeling Multilevel Data Structures." American Journal of Political Science 46, 1, 218-237.

Traugott, Michael and John Katosh. 1979. "Response Validity in Surveys of Voting Behavior." Public Opinion Quarterly 43, 359-377.

U.S. Census Bureau, 2002. "Voting and Registration in the Election of November 2000." http: //www . census.gov/prod/2002pubs/p20-542.pdf.

Verba, Sidney, Kay L. Schlozman, and Henry E. Brady. 1995. Voice and Equality: Civic Voluntarism in American Politics. Cambridge: Harvard University Press.

Vercellotti, Timothy and David Anderson, 2006. "Protecting the franchise, or restricting it? The effects of voter identification requirements on turnout." Manuscript, Rutgers University.

Western, Bruce. 1998. "Causal Heterogeneity in Comparative Research: A Bayesian Hierarchical Modeling Approach." American Journal of Political Science 42, 12331259.

Wolfinger, Raymond E. and Stephen J. Rosenstone. 1978. "The Effect of Registration Laws on Voter Turnout." American Political Science Review 72, 1, 22-45. 